\begin{tabular}{c|c|l|}
\cline { 2 - 3 } CRITICAL & $\begin{array}{l}\text { Western Ghats } \\
\text { ECOSYSTEM } \\
\text { PARTNERSHP FUND }\end{array}$ & Special Series \\
\cline { 2 - 3 }
\end{tabular}

\title{
Streamside amphibian communities in plantations and a rainforest fragment in the Anamalai hills, India
}

\author{
Ranjini Murali ${ }^{1}$ \& T.R. Shankar Raman ${ }^{2}$ \\ 1,2 Nature Conservation Foundation, 3076/5, $4^{\text {th }}$ Cross, Gokulam Park, Mysore, Karnataka 570002, India \\ Email: ${ }^{1}$ ranjini@ncf-india.org (corresponding author), ${ }^{2}$ trsr@ncf-india.org
}

Date of publication (online): 26 August 2012 Date of publication (print): 26 August 2012 ISSN $0974-7907$ (online) | 0974-7893 (print)

Editor: Sanjay Molur

\section{Manuscript details:}

Ms \# 02829

Received 09 June 2011

Final received 27 February 2012

Finally accepted 07 August 2012

Citation: Murali, R. \& T.R.S. Raman (2012). Streamside amphibian communities in plantations and a rainforest fragment in the Anamala hills, India. Journal of Threatened Taxa 4(9): 2849-2856.

Copyright: () Ranjini Murali \& T.R. Shankar Raman 2012. Creative Commons Attribution 3.0 Unported License. JoTT allows unrestricted use of this article in any medium for non-profit purposes, reproduction and distribution by providing adequate credit to the authors and the source of publication.

Author Details: See end of this article.

Author Contribution: The first author participated in study design, carried out the field work, analysis, and writing. The second author helped design the study, analyse data, and write the manuscript.

Acknowledgements: This study formed part of the rainforest restoration and sustainable agriculture project, financially supported by the Ecosystems Grant Programme of the Netherlands Committee for the IUCN, and the Critical Ecosystems Partnership Fund (CEPF) We are grateful to Tata Coffee Ltd. and Parry Agro Industries Ltd. for permission to work in their estates, and to Dinesh and Kannan for field assistance. We are very grateful to Dr. K. V. Gururaja, Saloni Bhatia, and Sachin Rai for their help with the identification of amphibians and to the reviewers for helpful suggestions that improved the manuscript. We thank our colleagues, Divya Mudappa, M. Ananda Kumar and P. Jeganathan, for discussions and help.

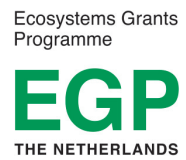

(1)

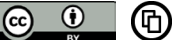

OPEN ACCESS | FREE DOWNLOAD
Abstract: Stream amphibian communities, occupying a sensitive environment, are often useful indicators of effects of adjoining land uses. We compared abundance and community composition of anuran amphibians along streams in tea monoculture, shade coffee plantation, and a rainforest fragment in Old Valparai area of the Anamalai hills. Overall species density and rarefaction species richness was the highest in rainforest fragment and did not vary between the coffee and tea land uses. Densities of certain taxa, and consequently community composition, varied significantly among the land uses, being greater between rainforest fragment and tea monoculture with shade coffee being intermediate. Observed changes are probably related to streamside alteration due to land use, suggesting the need to retain shade tree cover and remnant riparian rainforest vegetation as buffers along streams

Keywords: Herpetofauna, shade coffee, species richness, tea plantation, Western Ghats.

\section{INTRODUCTION}

Habitat alteration, fragmentation, and destruction are the greatest threats to biodiversity worldwide (Vitousek et al. 1997), especially in tropical zones where diversity is high and forests are being transformed at a rapid rate (Pineda \& Halffter 2004). The negative effects of these threats include decreased species richness and abundance, changes in species composition, and loss of genetic diversity (Saunders et al. 1991; Turner 1996; Laurance et al. 2002; Bell \& Donnelly 2006). There is also increasing concern over the impacts of such threats on freshwater ecosystems (Strayer \& Dudgeon 2010), particularly streams and rivers (Collier 2011). Streams and stream-dependent organisms are particularly sensitive and most likely to be affected by such changes in land use (Welsh \& Ollivier 1998; Sreekantha et al. 2007; Gururaja et al. 2008), especially in plantations where they are susceptible to agro-chemical drift, erosion and run-off (Logan 1993).

In the tropics, amphibians are good biological indicators of stream quality for several reasons. They usually have a bi-phasic life cycle with

This article forms part of a special series on the Western Ghats of India, disseminating the results of work supported by the Critical Ecosystem Partnership Fund (CEPF), a joint initiative of l'Agence Française de Développement, Conservation International, the Global Environment Facility, the Government of Japan, the MacArthur Foundation and the World Bank. A fundamental goal of CEPF is to ensure civil society is engaged in biodiversity conservation. Implementation of the CEPF investment program in the Western Ghats is led and coordinated by the Ashoka Trust for Research in Ecology and the Environment (ATREE) 
an aquatic larval stage and a terrestrial adult stage, their highly permeable skin makes them extremely sensitive to physical and chemical changes in their environment, and they occur at high densities in the tropical environments as important primary, mid-level, and top consumers (Wyman 1990; Wake 1991; Blaustein et al. 1994; Bell \& Donnelly 2006). During their aquatic stage, many amphibian larvae are susceptible to even minor changes in the stream environment because of their specialised use of the stream microhabitats (Welsh \& Ollivier 1998). Depending on the availability of breeding habitats and the dispersal ability of species, streams in a region can vary considerably in amphibian diversity and this variation can greatly influence local and regional amphibian species diversity (Krishna et al. 2005; Vasudevan et al. 2006).

The Western Ghats mountains, a biodiversity hotspot, extend for nearly $1600 \mathrm{~km}$ (from $8^{\circ} \mathrm{N}$ to $21^{\circ} \mathrm{N}$ ) along the west coast of India. Considerable tracts in the wetter and higher reaches, once covered by tropical rainforests are now dominated by plantations of tea, coffee, rubber, and cardamom with isolated fragments of forests and other areas of conservation value (Kumar et al. 2004; Das et al. 2006; Bali et al. 2007; Dolia et al. 2008). The region has a high diversity and endemism of amphibian species with 181 known species, (including new species described in recent years) of which $159(88 \%)$ are endemic to the Western Ghats (Aravind \& Gururaja 2011; Bhatta et al. 2011; Biju et al. 2011; Dinesh \& Radhakrishna 2011; Zachariah et al. 2011a,b). There is need for better documentation of the animal communities of tropical streams in the Western Ghats and the relationship between community structure and terrestrial landscape elements or land-uses (Krishna et al. 2005; Sreekantha et al. 2007; Gururaja et al. 2008; Karthick et al. 2011; Prakash et al. 2012).

Here, we evaluate the influence of land use on stream anuran diversity and density in the Western Ghats of southern India during the monsoon season. Earlier research from other parts of the Western Ghats has shown that amphibians can be sensitive indicators of change in habitat and land-use (Daniels 2003; Krishna et al. 2005; Gururaja et al. 2008). We extend this work to a fragmented landscape in the Anamalai hills where we compare the occurrence, abundance, and species composition of anurans along streams in three land uses: monoculture tea plantation, shade coffee plantation, and rainforest fragment. This study aimed to understand stream amphibian community response to alterations in land use in order to help in formulating strategies for species conservation in human-dominated landscapes.

\section{MATERIALS AND METHODS}

This study was conducted during July and August 2010 (southwest monsoon season) in the Valparai plateau in the Tamil Nadu part of the Anamalai hills in the southern Western Ghats. The Valparai plateau spans an area of $220 \mathrm{~km}^{2}$ with plantations of tea (Camellia sinensis), coffee (Arabica: Coffea arabica, Robusta: C. canephora), Eucalyptus, and cardamom (Elettaria cardamomum) plantations with around 40 rainforest fragments embedded in the landscape matrix (Mudappa \& Raman 2007). The Valparai plateau lies within a larger landscape adjoining the Anamalai Tiger Reserve $\left(958 \mathrm{~km}^{2}, 10^{\circ} 12^{\prime}-10^{0} 35^{\prime} \mathrm{N}\right.$ and $76^{\circ} 49^{\prime}-$ $77^{\circ} 24^{\prime} \mathrm{E}$ ) to the north and east in Tamil Nadu, and reserved forests and the Parambikulam Tiger Reserve to the south and west in Kerala.

The selected sites included tea and coffee plantation in Velonie Estate, and Tata Finlay (Old Valparai) rainforest fragment, all of which were within a $2 \mathrm{~km}$ radius and at an altitude of c. $1000 \mathrm{~m}$ (Image 1). Sampling was carried out along a first order and fourth order stream in both coffee and tea plantations, while only first order stream was available within the $32 \mathrm{ha}$ rainforest fragment for sampling. The same fourth order stream flowed through the tea and coffee. The first order streams in the coffee and the tea estate were both around $100 \mathrm{~m}$ long.

Visual encounter surveys (Heyer et al. 1994) were carried out in quadrats $50 \mathrm{~m}$ long and $4 \mathrm{~m}$ wide. Seven separate quadrats were sampled in each habitat, four sampled once and three sampled on two occasions yielding a total of 10 samples in each land-use type. As the sampling in the repeat quadrats was carried out at least six weeks apart, they are considered independent samples for the purpose of the present analysis. Five quadrats were along the fourth order stream in the coffee and tea estate and two quadrats were along the first order streams.

All quadrat surveys were carried out at night between 1900 and $2000 \mathrm{hr}$. Two observers surveyed 


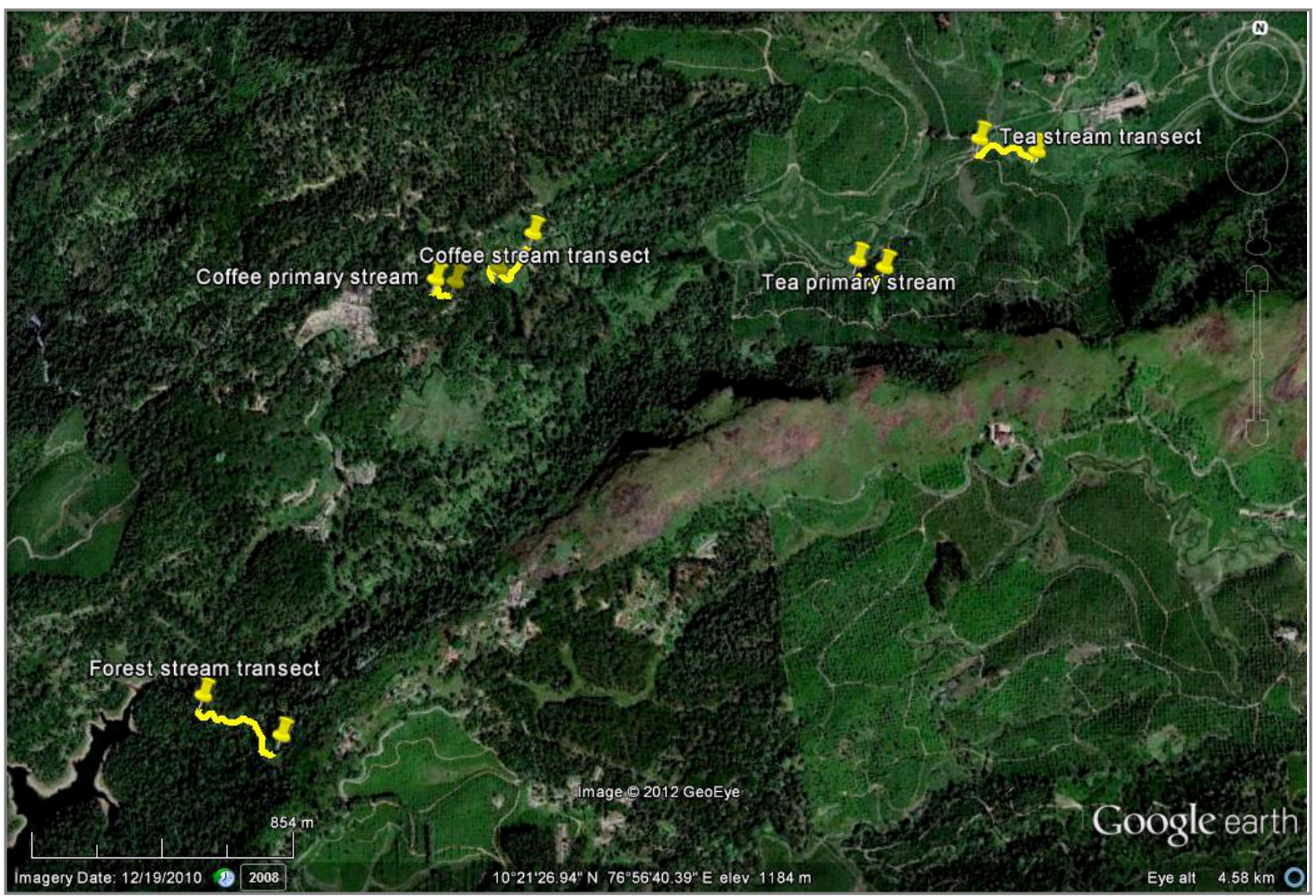

Image 1. Map showing locations of start and end points along stream transects (yellow lines) in the Valparai plateau, Anamalai hills (Courtesy: Google Earth).

each quadrat using torches to look for amphibians while walking very slowly to complete each quadrat in $60 \mathrm{~min}$. No stones or logs were overturned along the site so as to cause minimum disturbance to the habitat and shrubs (coffee and tea, in the case of plantations) were also scanned during the sampling. Most amphibians were identified in the field. We made no specimen collections and minimised handling to avoid harm or disturbance to amphibians. Photographs were taken of amphibians that could not be identified on field for later identification using field guides (Daniel 2002), taxonomic literature (Kuramoto et al. 2007; Biju \& Bossuyt 2009), and consultation with experts (K.V. Gururaja, Sachin Rai, Saloni Bhatia). All species belonging to the genus Fejervarya and Raorchestes were identified only to the genus level as proper identification would require closer taxonomic and genetic analysis. Further, all young ones were excluded from this study.

Species diversity of amphibians was analysed both as species density (number of species per quadrat) as well as species richness (number of species for a standardised sample of 100 individuals) following Gotelli \& Colwell (2001). Estimates of species richness (and corresponding 95\% confidence intervals) through rarefaction analysis were made using the program EcoSim (Gotelli \& Entsminger 2009). Amphibian density was measured as the number of amphibians per quadrat (density of individuals) for both total individuals (total density) as well as for individual taxa. We used one-way analysis of variance (ANOVA) followed by Tukey's HSD tests to examine statistical significance of differences among land uses in species density and amphibian densities (total density and individual taxa). For individual taxa, ANOVA was performed only for those taxa where more than 10 individuals were observed (i.e., Duttaphrynus sp. and Indirana sp. were excluded). ANOVA and Tukey HSD tests were performed using the $\mathrm{R}$ statistical and programming environment (version 2.10, R Development Core Team 2009). Amphibian species composition across sites was analysed by non-metric multi-dimensional scaling (MDS) ordination of the Bray-Curtis dissimilarity matrix of quadrats, using the software PRIMER (Clarke \& Warwick 1994; Clarke \& Gorley 2001). Significance of variation in community composition was assessed using analysis of similarities (ANOSIM) using PRIMER (Clarke \& Warwick 1994). 

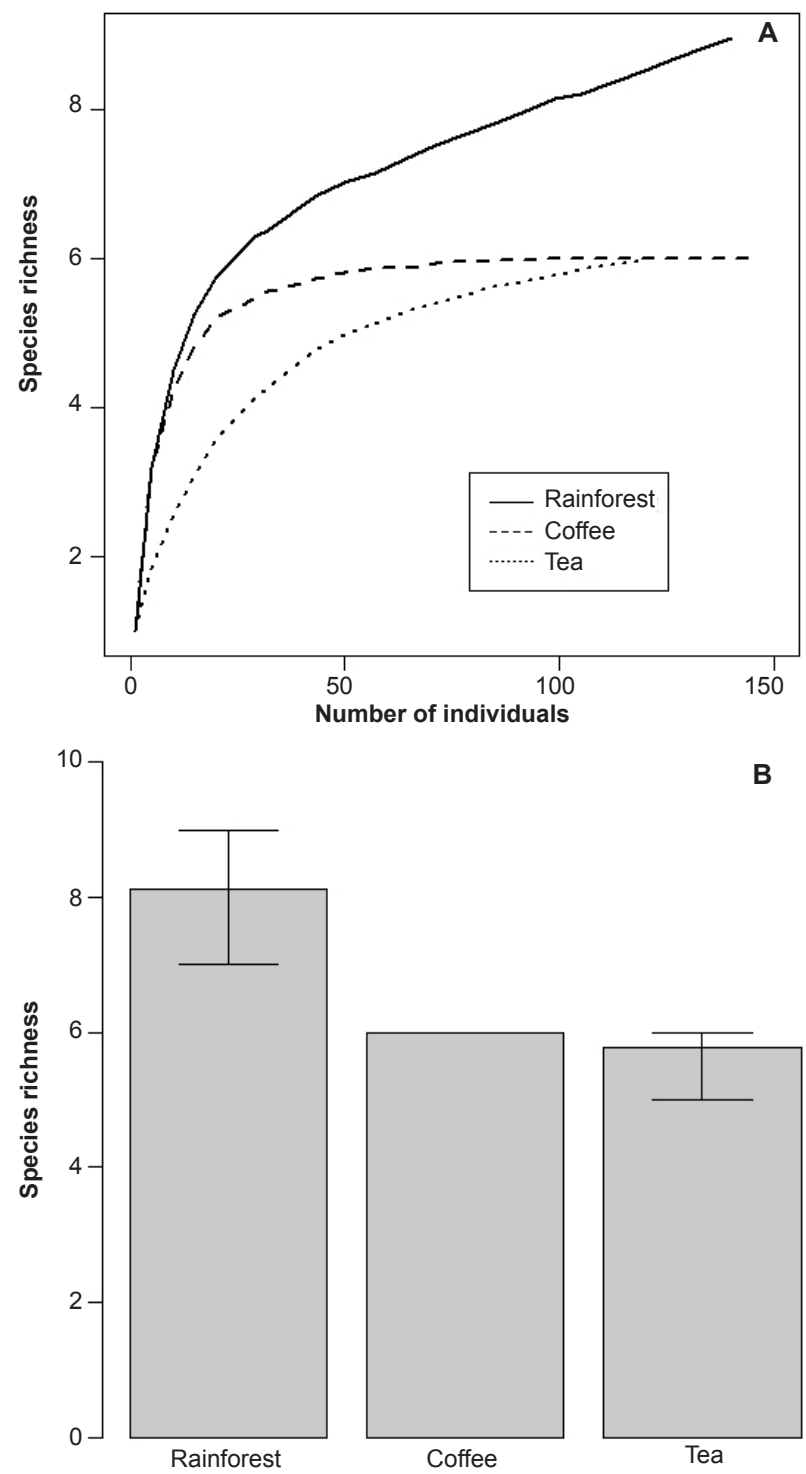

Figure 1. Amphibian diversity in relation to three landuse types in the Anamalai hills: (A) rarefaction curves of species richness, (B) comparison of species richness for a standardised sample of 100 individuals (vertical bars are $95 \%$ confidence intervals).

\section{RESULTS}

We recorded 413 individuals belonging to 10 different anuran amphibian taxa from the three different land uses: 149 individuals from coffee, 142 from rainforest fragment, and 122 from tea plantation (Table 1). The number of taxa recorded was higher (9) in the rainforest fragment than in coffee (6) and tea (6). This was also reflected in the rarefaction analysis of species richness (Fig. 1a) and comparisons of the number of species for a standardised sample of 100 individuals revealed that species richness was higher in rainforest fragment than in the plantations (Fig. 1b). Analysis of species density (number of species per quadrat) likewise showed statistically significant differences (ANOVA, $\mathrm{F}_{(2,27)}=5.94, \mathrm{P}=0.0073$ ), with the rainforest fragment having the highest species density (mean \pm S.E: $4.3 \pm 1.36$ species/quadrat), followed by coffee $(3.4 \pm 1.06)$, and tea $(2.6 \pm 0.82)$. The difference between rainforest fragment and tea plantation was found to be statistically significant in the Tukey HSD test $(\mathrm{P}<0.05)$.

While total amphibian density (individuals / 200 $\mathrm{m}^{2} \pm \mathrm{SE}$ ) did not vary among the three land-uses (Table 1), density of individual taxa varied. Tea

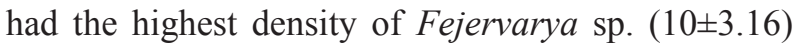
and the rainforest fragment had the least $(2.4 \pm 0.76)$, with density in coffee being intermediate but not significantly different from tea. Micrixalus sp. and Nyctibatrachus sp. were recorded only in the rainforest fragment. Raorchestes $\mathrm{sp}$. was significantly higher in density in coffee $(2.9 \pm 0.92)$, compared to tea and rainforest fragment that had the same density (0.7 \pm 0.22$)$. Euphlyctis cyanophlyctis was not recorded in the rainforest fragment and its density was highest in coffee $(2.4 \pm 0.76)$ followed by tea $(0.6 \pm 0.19)$, although the difference between the plantations was not statistically significant (Table 1).

Non-metric multi-dimensional scaling ordination (Fig. 2) suggests that species composition in rainforest fragment quadrats varied from tea quadrats, with coffee quadrats occupying an intermediate position. Analysis of similarities (ANOSIM) results showed that variation in amphibian community composition among the three land-use types was statistically significant (global $\mathrm{R}=0.438, \mathrm{P}<0.001$ ). Pair-wise comparisons between land-use types indicated statistically significant variation between rainforest fragment and tea $(\mathrm{R}=0.641, \mathrm{P}<0.001)$, rainforest fragment and coffee $(\mathrm{R}=0.522, \mathrm{P}=0.002)$, and coffee and tea $(\mathrm{R}=0.188, \mathrm{P}=0.015)$.

\section{DISCUSSION}

This study showed that streamside anuran species richness was highest in the rainforest fragment and decreased in coffee and tea plantations. Decreasing canopy cover resulting in higher temperatures, increasing wind velocity and decreasing soil and 
Table 1. Amphibian density along streams in the three land-use types in the Anamalai hills. Tabled values represent density as individuals / $200 \mathrm{~m}^{2} \pm \mathrm{SE}$, total number of individuals recorded (in parantheses), and statistics from 1-way analysis of variance (ANOVA).

\begin{tabular}{|c|c|c|c|c|c|}
\hline Taxon & Tea* $^{*}$ & Coffee* $^{*}$ & Rainforest* & ANOVA $F_{(2,27)}$ & $\mathbf{P}$ \\
\hline All & $12.2 \pm 1.47(122)$ & $14.9 \pm 2.09(149)$ & $14.2 \pm 1.45(142)$ & 0.68 & 0.514 \\
\hline Duttaphrynus melanostictus & $0.6 \pm 0.31(6)$ & $0.4 \pm 0.22(4)$ & $0.1 \pm 0.10(1)$ & 1.25 & 0.303 \\
\hline Euphlyctis cyanophlyctis & $0.6 \pm 0.27^{\mathrm{ab}}(6)$ & $2.4 \pm 0.86^{b}(24)$ & $0^{\mathrm{a}}(0)$ & 5.79 & 0.008 \\
\hline Fejervarya sp. & $10 \pm 1.57^{b}(100)$ & $6.3 \pm 0.98^{\mathrm{ab}}(63)$ & $2.4 \pm 1.24^{\mathrm{a}}(24)$ & 8.73 & 0.001 \\
\hline Hylarana aurantiaca (Image 2) & $0.2 \pm 0.13(2)$ & $1.8 \pm 1.06(18)$ & $2.5 \pm 0.87(25)$ & 2.19 & 0.132 \\
\hline Hylarana temporalis (Image 3) & $0(0)$ & $1.1 \pm 0.72(11)$ & $1.4 \pm 0.31(14)$ & 2.65 & 0.089 \\
\hline Nyctibatrachus sp. & $0^{\mathrm{b}}(0)$ & $0^{\mathrm{b}}(0)$ & $1 \pm 0.30^{\mathrm{a}}(10)$ & ** & ** \\
\hline Micrixalus sp. (Image 4) & $0^{\mathrm{b}}(0)$ & $0^{\mathrm{b}}(0)$ & $5.9 \pm 1.80^{\mathrm{a}}(59)$ & ** & ** \\
\hline Raorchestes sp. & $0.7 \pm 0.26^{\mathrm{a}}(7)$ & $2.9 \pm 0.94^{\mathrm{b}}(29)$ & $0.7 \pm 0.21^{\mathrm{a}}(7)$ & 4.89 & 0.015 \\
\hline Duttaphrynus sp. & $0(0)$ & $0(0)$ & $0.1(1)$ & - & - \\
\hline Indirana sp. & $0.1(1)$ & $0(0)$ & $0.1(1)$ & - & - \\
\hline
\end{tabular}

*Different superscripted alphabets indicate statistically significant difference from each other as per Tukey HSD multiple comparisons test.

${ }^{* *}$ Although ANOVA outputs indicated significantly higher density in rainforest, the statistical test results were superfluous because these two taxa were completely absent in the samples from plantations.

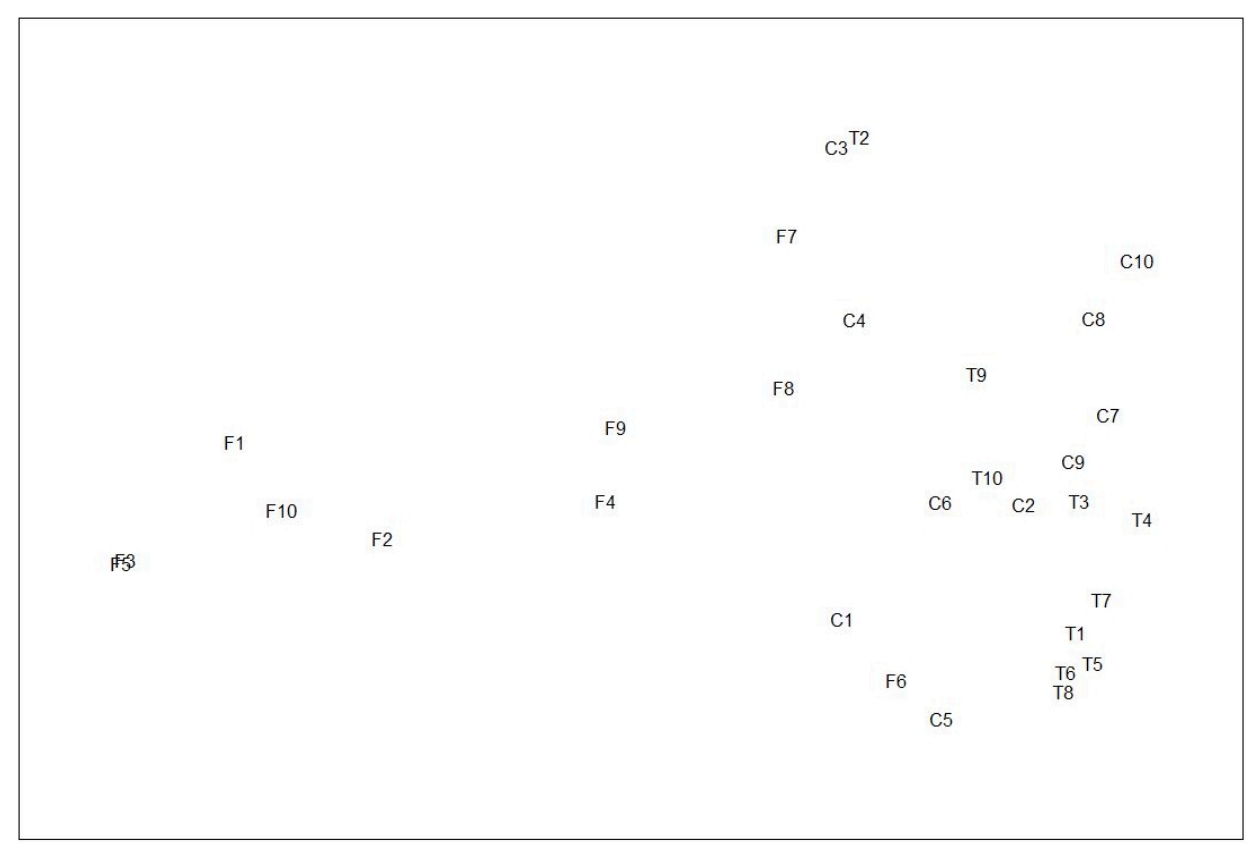

Figure 2. Variation in amphibian species composition in quadrat samples along streams in three land-use types in the Anamalai hills using non-metric multi-dimensional scaling (MDS) ordination.

Quadrat labels: F - Rainforest fragment, C - Coffee plantation, and T - Tea plantation.

atmospheric humidity (Saunders et al. 1991; Pineda \& Halffter 2004) could account for the decreased species richness in coffee and tea plantations. Similarly, Krishna et al. (2005) reported a decrease in richness between forest and coffee and cardamom land uses in the central Western Ghats.

Studies on conservation value of plantations in the Western Ghats for other taxonomic groups have shown that a diversity of species use these plantations, including many species typical to forests of the region as well as more widely distributed species of more open habitats (Raman 2006; Bali et al. 2007; Dolia et al. 2008; Anand et al. 2008). Daniels (2003) also opined that tea plantations were capable of supporting many amphibian species. Similarly, our study indicates that a number of anurans use the coffee and tea plantations, 


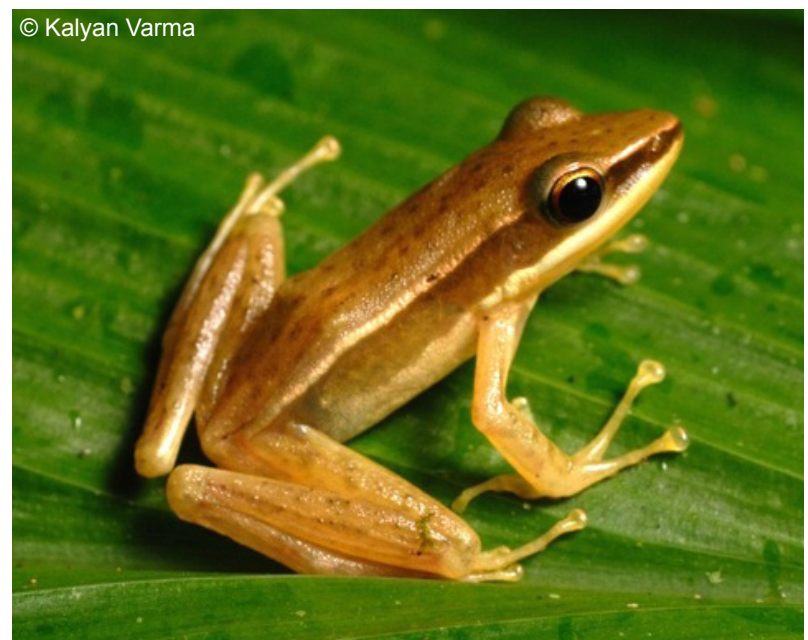

Image 2. Hylarana aurantiaca

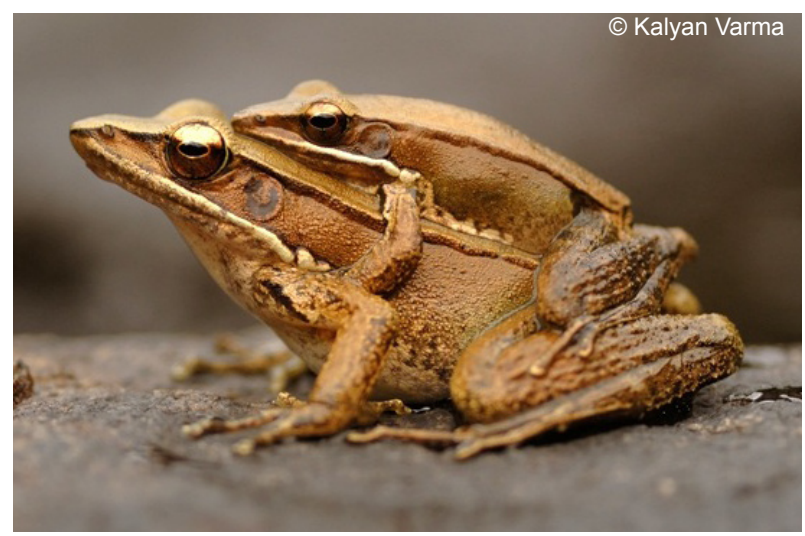

Image 3. Hylarana temporalis

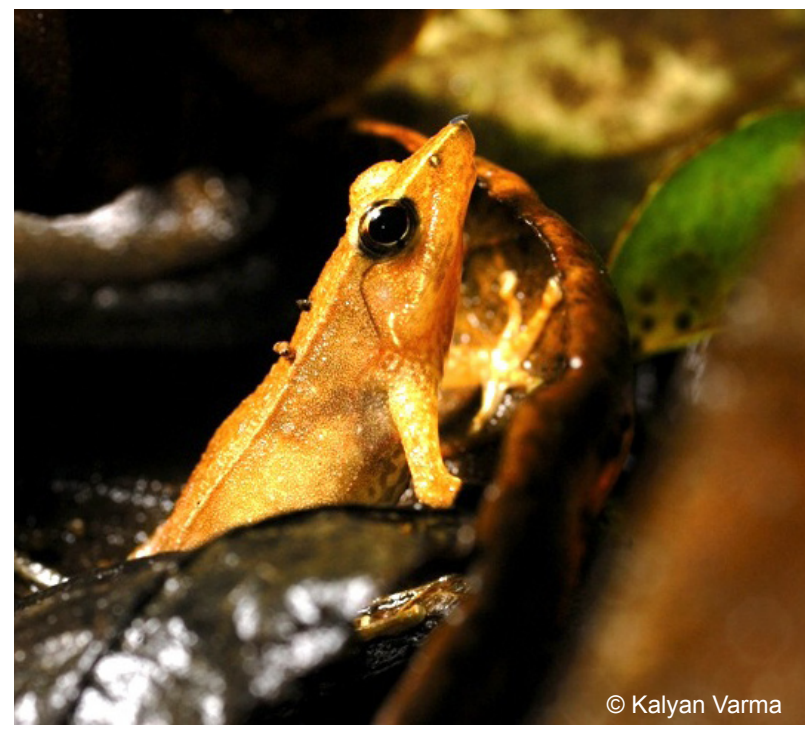

Image 4. Micrixalus sp. although the diversity is lower than in the rainforest fragment.

Species composition often varies among land use types, and species with specific ecological requirements that are not available in modified land uses may be more affected than others (Waltert et al. 2004). In the present study, Micrixalus sp. and Nyctibatrachus sp. (genera of mainly forest-dependent species endemic to the Western Ghats; Aravind \& Gururaja 2011) were the most affected by land use, being absent from coffee and tea plantations. Krishna et al. (2005) also reported the absence of Micrixalus sp. from coffee plantations. The highest number of Fejervarya sp. was found in the tea estate. Fejervarya are generalists known to occur near still and stagnant water where they are known to breed (Kuramoto et al. 2007), such habitats were available in the streams through tea estate where due to open canopy and dense growth of grasses and sedges, the streams were partly swampy along the valley. Daniels (2003) also noted the common occurrence of generalist anurans such as Fejervarya sp. and Duttaphrynus melanostictus in his survey in tea plantations. Euphlyctis cyanophlyctis was completely absent in the forest fragment and was sighted mainly in coffee with very few individuals recorded in tea. This species is aquatic or semi-aquatic and usually live half submerged in water or at the water's edge in ponds, wetlands, paddy fields and ditches (Joshy et al. 2009). Andrews et al. (2005) and Krishna et al. (2005) also reported an absence of Euphlyctis sp. from rainforest. Our results showing more generalist species in plantations and more forest-dependent endemic species in fragments are consistent with Gururaja et al.'s (2008) observation that human induced changes in land-uses, canopy cover, and hydrological regimes may support generalist amphibian species whereas less disturbed forest areas with higher canopy cover, tree density and rainfall support more endemic species.

The differences in species composition may be due to variation in streamside vegetation and environment, including decreased riparian vegetation and decreased clear-flowing water in the plantations, especially the highly modified tea monocultures (as noticed in a parallel study in the same landscape; Prakash et al. 2012). It is unlikely that variation in species composition is due to variation in stream order as the first and fourth order streams in the coffee and the tea plantations did not differ noticeably from each other, 
while clearly differing from the first order stream through the rainforest fragment. As amphibians often display a patchy distribution linked to microclimate conditions or spawning places (Zimmerman \& Bierregaard 1986), such factors may be more influential on variation in species composition due to land use change.

Despite some clear patterns, the present study had several limitations. Being carried out during July and August, it is representative only of the southwest monsoon season. Besides canopy species being completely omitted, other species may have been missed as well as the observers tried to be as nonintrusive as possible. Visibility also varied across the three land uses, being highest in tea, followed by coffee, and then rainforest fragment, suggesting that the higher richness in the latter may only be a conservative estimate. However, the species richness in the coffee land use may be higher as Raorchestes sp., identified only to genus, may represent several species. We conclude that a longer-term study of amphibian species in coffee and tea plantations can provide a more comprehensive view of the effects of land use change, of which the present study forms a useful baseline. Such research can also help pinpoint better agricultural land-use practices that minimise or avoid negative environmental impacts on streams (Logan 1993), and may be linked to opportunities for sustainable agriculture certification for plantation businesses that adopt such better land-use practices (Aerts et al. 2010).

\section{REFERENCES}

Aerts, J., D. Mudappa \& T.R.S. Raman (2010). Coffee, conservation, and Rainforest Alliance certification: opportunities for Indian coffee. Planters' Chronicle 106(12): $15-26$.

Anand, M.O., J. Krishnaswamy \& A. Das (2008). Proximity to forests drives bird conservation value of shade-coffee plantations: Implications for certification. Ecological Applications 18: 1754-1763.

Andrews, M.I., S. George \& J. Joseph (2005). Amphibians in protected areas of Kerala. Zoos' Print Journal 20(4): 1823 1831.

Aravind, N.A. \& K.V. Gururaja (2011). Amphibians of the Western Ghats. Theme paper, Western Ghats Ecology Expert Panel, Ministry of Environment and Forests, India.

Bali, A., A. Kumar \& J. Krishnaswamy (2007). The mammalian communities in coffee plantations around a protected area in the Western Ghats, India. Biological Conservation 139: 93-102.

Bell, K.E. \& M.A. Donnelly (2006). Influence of forest fragmentation on community structure of frogs and lizards in Northeastern Costa Rica. Conservation Biology 20: 17501760.

Bhatta, G., K.P. Dinesh, P. Prashanth, N. Kulkarni \& C. Radhakrishnan (2011). A new caecilian Ichthyophis davidi sp. nov. (Gymnophiona: Ichthyophiidae): the largest striped caecilian from the Western Ghats. Current Science 101: 1015-1018.

Biju, S.D. \& F. Bossuyt (2009). Systematics and phenology of Philautus Gistel, 1848 (Anura Rhacophoridae) in the Western Ghats of India with description of 12 new species. Zoological Journal of the Linnean Society 155: 374-444.

Biju, S.D., I.V. Bocxlaer, S. Mahony, K.P. Dinesh, C. Radhakrishnan, A. Zachariah, V. Giri \& F. Bossuyt (2011). A taxonomic review of the Night Frog genus Nyctibatrachus Boulenger, 1882 in the Western Ghats, India (Anura: Nyctibatrachidae) with description of twelve new species. Zootaxa 3029: 1-96.

Blaustein, A.R., D.B. Wake \& W.P. Sousa (1994). Amphibian declines: judging stability, persistence, and susceptibility of populations to local and global extinctions. Conservation Biology 8: 60-71.

Clarke, K.R. \& R.N. Gorley (2001). Primer v5: User manual/ tutorial. PRIMER-E, Plymouth.

Clarke, K.R. \& R.M. Warwick (1994). Change in marine communities: An approach to statistical analysis and interpretation. Plymouth Marine Laboratory, Plymouth.

Collier, K.J. (2011). The rapid rise of streams and rivers in conservation assessment. Aquatic Conservation: Marine and Freshwater Ecosystems 21: 397-400.

Daniel, J.C. (2002). The Book of Indian Reptiles and Amphibians. Bombay Natural History Society. Oxford University Press, 238pp.

Daniels, R.J.R. (2003). Impact of tea cultivation on anurans in the Western Ghats. Current Science 85: 1415-1421.

Das, A., J. Krishnaswamy, K.S. Bawa, M.C. Kiran, V. Srinivas, N.S. Kumar \& K.U. Karanth (2006). Prioritisation of conservation areas in the Western Ghats, India. Biological Conservation 133: 16-31.

Dinesh, K.P. \& C. Radhakrishnan (2011). Checklist of amphibians of Western Ghats. Frogleg 16: 15-21.

Dolia, J., M.S. Devy, N.A. Aravind \& A. Kumar (2008). Adult butterfly communities in coffee plantations around a protected area in the Western Ghats, India. Animal Conservation 11: 26-34.

Gotelli, N.J. \& R.K. Colwell (2001). Quantifying biodiversity: procedures and pitfalls in the measurement and comparison of species richness. Ecology Letters 4: 379-391.

Gotelli, N.J. \& G.L. Entsminger (2009). EcoSim: Null models software for ecology. Version 7. Acquired Intelligence Inc. \& Kesey-Bear. Jericho, VT $05465<$ http://garyentsminger. com/ecosim/index.htm> 
Gururaja, K.V., A. Sameer \& T.V. Ramachandra (2008). Influence of land-use changes in river basins on diversity and distribution of amphibians, pp. 33-42. In: Ramachandra, T.V. (ed.). Environment Education for Ecosystem Conservation. Capital Publishing Company, New Delhi.

Heyer, W.R., M.A. Donnelley, R.W. McDiarmid, L.C. Hayek, \& M.S. Foster (eds.) (1994). Measuring and Monitoring Biological Diversity: Standard Methods for Amphibians. Smithsonian Institution Press, 384pp.

Joshy, S.H., M.S. Alam, A. Kurabayashi, M. Sumida \& M. Kuramoto (2009). Two new species of genus Euphlyctis (Anura, Ranidae) from southwestern India, revealed by molecular and morphological comparisons. Alytes 26: 97 116.

Karthick, B., M.K. Mahesh \& T.V. Ramachandra (2011). Nestedness pattern in stream diatom assemblages of central Western Ghats. Current Science 100(4): 552-558.

Krishna, S.N., S.B. Krishna \& K.K. Vijayalaxmi (2005). Variation in anuran abundance along the streams of the Western Ghats, India. Herpetological Journal 15: 167-172.

Kumar, A., R. Pethiyagoda \& D. Mudappa (2004). Western Ghats and Sri Lanka, pp.152-157. In: Mittermeier, R.A., P.R. Gil, M. Hoffmann, J. Pilgrim, T. Brooks, C.G. Mittermeier, J. Lamoureux \& G.A.B. da Fonseca (eds.)Hotspots Revisited - Earth's Biologically Richest and Most Endangered Ecoregions. CEMEX, Mexico.

Kuramoto, M., S.H. Joshy, A. Kurabayashi \& M. Sumida (2007). The genus Fejervarya (Anura: Ranidae) in central Western Ghats, India, with descriptions of four new cryptic species. Current Herpetology 26: 81-105.

Laurance, W.F., T.E. Lovejoy, H.L. Vasconcelos, E.M. Bruna, R.K. Didham, P.C. Stouffer, C. Gascon, R.O. Bierregaard, S.G. Laurance \& E. Sampaio (2002). Ecosystem decay of Amazonian forest fragments: a 22-year investigation. Conservation Biology 16: 605-618.

Logan, J.T. (1993). Agricultural best management practices for water pollution control: current issues. Agriculture, Ecosystems and Environment 46: 223-231.

Mudappa, D. \& T.R.S. Raman (2007). Rainforest restoration and wildlife conservation on private lands in the Valparai plateau, Western Ghats, India, pp. 210-240. In: Shahabuddin, G. \& M. Rangarajan (eds.). Making Conservation Work. Permanent Black, Ranikhet.

Pineda, E. \& G. Halffter (2004). Species diversity and habitat fragmentation: frogs in a tropical montane landscape in Mexico. Biological Conservation 117: 499-508.

Prakash, N., D. Mudappa, T.R.S. Raman \& A. Kumar (2012). Conservation of the Asian Small-clawed Otter (Aonyx cinereus) in human-modified landscapes, Western Ghats, India. Tropical Conservation Science 5: 67-78.

R Development Core Team (2009). R: A language and environment for statistical computing. R Foundation for Statistical Computing,Vienna, Austria. ISBN 3-900051-070, URL < http://www.r-project.org/>

Raman, T.R.S. (2006). Effects of habitat structure and adjacent habitats on birds in tropical rainforest fragments and shaded plantations in the Western Ghats, India. Biodiversity and Conservation 15: 1577-1607.

Saunders, D.A., R.J. Hobbs \& C.R. Margules (1991). Biological consequences of ecosystem fragmentation: a review. Conservation Biology 5: 18-30.

Sreekantha, M.D., S. Chandran, D.K. Mesta, G.R. Rao, K.V. Gururaja \& T.V. Ramachandra (2007). Fish diversity in relation to landscape and vegetation in central Western Ghats, India. Current Science 92(11): 1592-1603.

Strayer, D.L. \& D. Dudgeon (2010). Freshwater biodiversity conservation: recent progress and future challenges. Journal of the North American Benthological Society 29: 344-358.

Turner, I.M. (1996). Species loss in fragments of tropical rain forest: a review of the evidence. Journal of Applied Ecology 33: 200-209.

Vasudevan, K., A. Kumar \& R. Chellam (2006). Species turnover: the case of stream amphibians of rainforests in the Western Ghats, southern India. Biodiversity and Conservation 34: 3515-3525.

Vitousek, P.M., H.A. Mooney, J. Lubchenco \& J.M. Melillo (1997). Human domination of Earth's ecosystems. Science 277: 494-499.

Waltert, M., A. Mardiastuti \& M. Muhlenberg (2004). Effects of land use on bird species richness in Sulawesi, Indonesia. Conservation Biology 18: 1339-1346.

Wake, D.B. (1991). Declining amphibian populations. Science 253: 860 .

Welsh, H.H. \& M.L. Ollivier (1998). Stream amphibians as indicators of ecosystem stress: A case study from California's Redwoods. Ecological Applications 8: 1118-1132.

Wyman, R.L. (1990). What's happening to the amphibians? Conservation Biology 4: 350-352.

Zachariah, A., K.P. Dinesh, E. Kunhikrishnan, S. Das, D.V. Raju, C. Radhakrishnan, M.J. Palot \& S. Kalesh (2011a). Nine new species of frogs of the genus Raorchestes (Amphibia: Anura: Rhacophoridae) from southern Western Ghats, India. Biosystematica 5: 25-48.

Zachariah, A., K.P. Dinesh, C. Radhakrishnan, E. Kunhikrishnan, M.J. Palot \& C.K. Vishnudas (2011b). A new species of Polypedates Tschudi (Amphibia: Anura: Rhacophoridae) from southern Western Ghats, Kerala, India. Biosystematica 5: 49-53.

Zimmerman, B.L. \& R.O. Bierregaard (1986). Relevance of the equilibrium theory of island biogeography and speciesarea relations to conservation with a case from Amazonia. Journal of Biogeography 13: 133-143.

Author Details: RANJINI MURALI worked as a Research Affiliate on this project and currently works as the Conservation Coordinator in the High Altitude Programme of the Nature Conservation Foundation (NCF).

T.R. SHANKAR RAMAN is a Senior Scientist with NCF working on rainforest restoration and conservation in the Western Ghats. 